\title{
Teaching Reform and Practice of Audio-visual Language Course
}

\author{
Tong Wang ${ }^{1, a,{ }^{*}}$, Tian $\mathrm{Xia}^{1}$, Jiaqi Wu ${ }^{1}$ and $\mathrm{Na} \mathrm{Wang}^{1}$ \\ ${ }^{1}$ Institute of Computer and Information Engineering, Shanghai Second Polytechnic University, \\ Shanghai, 201209, China \\ azjxywt@163.com
}

Keywords: Audio-visual language, Teaching reform, Practice.

\begin{abstract}
Audio-visual language is a core curriculum of digital media technology major. It is not a genuine language since it is composed of lights and sounds, namely audio-visual images instead of words or symbols. But the practice of this course is lack. The traditional theory way of teaching, has been far from meeting the needs of the whole teaching system. In our paper, we propose a new innovation of audio-visual language course which teach the students to grasp the theory knowledge and practice, more direct combination of theory and practice, finally master the audio-visual language of curriculum knowledge. The result showed that the using of new teaching method and curriculum are effective in audio-visual language teaching.
\end{abstract}

\section{Introduction}

If colleges want to meet the education model and improve the practice and innovation capability of graduates, first and foremost task is to strengthen the practice of teaching. With the rapid development of higher education in our country, there has been a complete and special education system. In fact, teaching could achieve a combination of theory and practice, book knowledge and practical application, and hands-brain combination [1].

Audio-visual language course, in the setting of digital media professional courses in many universities, is a cultural course learning. The purpose of this course is to enable students to understand the basic elements of the film, to understand the method of visual and auditory create reasonable, grasp the application of film camera language, master the skills and methods of film editing, accumulated experience and lay the foundation for the creation of excellent film[2].

Audio-visual language is a language of movie and television. It is not a genuine language since it is composed of lights and sounds, namely audio-visual images instead of words or symbols. However, although it is actually a quasi-language without grammar, it can still be brought under the category of a language because it can convey emotions and meanings just like any language does. Audio-visual language owes its cultural features, artistic quality and ways of communication. As to its culturalfeatures, it is a way of thinking of movies. As to its artistic quality, it is a technique of expression or say, sort of artistic form of movies which is reflected as assumption, uniqueness and montage in movies. As to its ways of communication, it is a system of sign coding for movies reflected as the shots cuts, shots reorganizations and sounds making. As a language too, characters in movies also reflect some ideologies inside. An ideology of the shots is created by the different shooting angels according to the variation of the plots and emotions in the movies. Audio-visual language applied in the creation of characters mainly devotes in the study of the narrative pattern of the shots, namely the way to deal with the relationship of sounds and pictures, the way to connect the shots and the lights and shadows in the whole movement according to our needs. Characters in movies spread information by images instead of languages. We can use the audio-visual language to analyze the variation of the characters in the shots, such as the change between movement and stillness of the characters, the use of music and the mobilization of colors in the creation of characters (We need to study the application of flowing colors in character creation as well since characters in the movies are constantly changing and moving) and the way to embody the effect of lights and shadows combined with the flowing colors. 
Most of the colleges and universities teaching style, is based on the traditional theory teaching. The assessment method is based on test. The traditional teaching mode, has not been adapt to the requirements of the professional development of digital media. Therefore, I carried out some exploration and try in the teaching process. In the premise of teaching students quickly grasp the theoretical knowledge, student can do the actual practice of training more directly to combine the theory and practice, finally to fully grasp the curriculum knowledge of audio-visual language.

\section{Current situation of Audio-visual language course}

Audio-visual language is a core curriculum of digital media technology major. The content covers relates to image, sound and film editing. Specifically, the first part is the basic knowledge of shooting; the second part is the acquisition, processing, processing knowledge of voice; the third part is the synthesis of the two parts. Of course, the effective presentation of audio-visual language learning outcomes is a film product. Therefore, how to do a good job of each part and the optimization and integration has become the key of audio-visual language learning.

In recent years, the comment of college graduates from employment sector is good, they think that the university graduates are active, full of passion, good at English and computer application, and know more about new developments in science and technology. However, there are also problems that some students who divorced from reality and just have high scores but less ability to solve practical problems. The same problem exists in the teaching process of audio-visual language.

Audio visual language as a basic course in major of digital media, the form of traditional teaching is mainly classroom teaching, supplemented classic film clips to watch. There are misunderstandings and problems which are not conducive to the of quality education in the aboved teaching process.

First of all, students generally believe that this is a basic theory course of film, which ignores the combination of theory and practice of creative learning. In fact, this course requires students to learn the classical theory of film language, combined with the analysis of actual case of film, and gradually formed the self-consciousness of "lens" and professional in mind, to guide the creation of film.

To achieve this goal, teaching of each of the main sections need to be closely combined with the practical experiment, students can truly understand and grasp the essence and concept. Second, teachers generally think that this is a primary theoretical foundation courses tend to focus on the concepts and works appreciation.

In fact, this course needs the creation and production practices. Again, based the teacher classroom teaching mode, the students tend to get good grades in all kinds of examination, but lack the ability to solve practical problems by using innovative thinking. It may stifle students' independent learning ability and innovation ability. It is difficult to cultivate suitable talents needed by the society.

\section{Teaching reform for audio-visual language}

We start with the internal structure of the knowledge system to seize the internal relations and laws of the various functional stages of the compilation process, using meaningful questions to guide students' positive thinking. Disclose theoretical difficulties and abstract concepts in audio-visual language by presenting problems to students. By answering questions from different perspectives, students can seek the principle and means to solve problems, thus guiding students to independently analysis and solve problem, deepening the understanding of audio-visual language and technology. Audio-visual language is a strong theoretical course. In order to visualize abstract problems to facilitate students to understand and apply knowledge points, the use of multimedia tools can present principle knowledge in the form of animation, graphics to transform static to dynamic, teach through lively activities to stimulate students' interest in learning[3]. 


\section{The reasonable arrangement of the theory and the practice}

Although there are some practice in the current arrangement of "visual language" course, but much less than the theoretical class hours. The arrangements of teaching steps are not reasonable. Firstly, a lot of theoretical courses are finished. Then, arrange a short practical training. Such teaching methods, students often feel boring in learning theory, later in the course of practice, the past learning has been forgotten.

The author thinks the reasonable teaching method should be: let the students master the simple theory of audio-visual language generally, arousing their interest in this course, and then go to practice. In the actual operation of creation, students can deepen understanding of the learned knowledge, also more aware of their lack of knowledge reserves. The next step is to return to the classroom teaching, so that students get the knowledge of the compariton in practice, sorting out the shortcomings and lack, targeted for the study of theoretical knowledge, and then again in practice and so on. So, to find problems, to solve the problem, so as to profound and complete grasp of the audio-visual language.

\section{Close integration of theory and practice of teaching}

Digital media technology is a strong operational expertise, audio-visual language courses to master good or bad, and ultimately reflected in the student's specific creation. To this end, the teaching of the functional of main visual elements, sufficient to enable students to complete the required scenario lens design (storyboard), to carry out one to one way to explain the practice, and the theory in the classroom teaching is more lively and efficient. In order to deepen students' understanding and application of knowledge, curriculum should highlight the practice of experimental teaching characteristics. In view of present situation of audio-visual language course, we try to make full use of the relevant courses to strengthen the practice teaching, experiment and practice teaching system in a unified form.

For example, photography course is a professional compulsory course for the major of digital media technology. The course covers the composition, scene, angle, the basic requirements of the screen shape, light and color on the screen image of the shape and depict scenes, the general method, rule, technique and its application of scene scheduling. Therefore, we integrated audio-visual language and photography courses. The audio-visual language class focuses on explaination of the function of the main visual elements, the analysis on the classic cases, students interactive exercises and strengthening the experiment practice. Photography class set specified scene practice, for the basic scenario which the teacher set, such as dialogue, speech, a straight walk, one or more students to use one or more seats in experimental film. The teacher explain the seat scheduling, scene, perspective, composition elements, the use of light and other related audio-visual language problems[4].

Many schools have opened a photography course, but generally exist defects of less class hours and teaching method is not mature. We can start from the imitation of a good movie, students only need to master the lens and the lens in the movie schedule, then guess the director's intention, and expressed the artistic conception, after this step the students can film according to the requirements proposed by the teacher, during the filming process try they can use the knowledge to express the effect the teacher required. Finally, students can freely express their desire to shoot the film. The shooting practice is required to be in the form of group, it also can exercise coordination and understanding of the exchange of knowledge.

\section{Increase the intensity of practice examination}

Traditional "visual language" assessment is based on written examinations. The scope of assessment content is only the selected textbooks, this will bring a lot of disadvantages, such as not know the students practical skills and proficiency in the use of what they have learned, and so on, from a certain point of view, the assessment is in order to constrain the enthusiasm of student learning, only to set the correct direction of the assessment, so that students can be organized to study, to grasp the knowledge they need. The assessment is put into two categories which are written examination and practical operations. Written examination based on knowledge mainly from some hard to check. This can master the understanding of the "visual language" in some definitions, tools and basic classification by student. The practical operation requires the students to form the 
group, solidarity and cooperation to the actual operation of what they have learned. Can also be a classmate as a group to complete the requirements of teachers, so from their own operations can better grasp of the text of the knowledge they have learned.

\section{Course Curriculum}

In projects-based experiments part, the two types of projects are validation experiments and comprehensive experiments. The former is tied in with the content of classroom instruction that is compiled by teachers according to the original rationale taught order to sync certain confirmatory experimental subject, allowing students to complete related practice one by one, and gradually expanding to improve the entire practice. The step-by-step method not only increases the sense of accomplishment and self-confidence of the students, but also enables them to develop a solid basis. It can also stimulate students' interest and enthusiasm in learning.

Certain scale comprehensive design experiment is essential to ensure the effect of practice. Students will be divided into several groups according to students and their topics of interest. Students selected the leader of each team. Each leader is equivalent to film director, and is responsible for the entire organization and coordination. Each member should put forward their own ideas and views of other team members to evaluate by listening to special reports, documentation, inspection, such as aspect, and then by the team leader determine the group's projects.

\section{Development of teachers' ability}

Practical ability of teachers is directly the effect of practice teaching. Therefore, in order to do a good job in the practice teaching, there must be excellent teachers with practical skills and strengthen the professional capacity of teachers. We must focus on doing the following things in developing teachers' practical ability:

First, let young teachers take turns to industrial and mining enterprises for some time to receive training and practice and improve their project quality. And select some large state owned enterprises to develop some bases for young teachers' training.

Second, build a team of teachers who are "Double Type"(teachers and engineers). Schools should encourage teachers to take part-time jobs in enterprises and support them to take part in educational conference, therefore they can improve their skills and learn new experiences from experts of famous university.

Third, if the number of teachers in current practice teaching is inadequate, schools could also create part-time teachers who come from enterprises with professional practical experience or skills.

Teachers also should insist on a combination of teaching and research, cite the latest scientific research and education reform into teaching.

\section{Summary}

Above teaching, practice test and evaluation, take the student as the center, to promote the development of students' personality and potential for the purpose. By strengthening the cultivation of students' visual thinking and creative skills, comprehensive reform has achieved initial success, The enthusiasm of the students was obviously enhanced, practical abilityand creative enthusiasm greatly enhance. The students have mastered the common expression of the elements of audio-visual language, can use montage thought to organize the scene tell the story. The practical operation ability of students' is enhanced and the quality of works is improved.

\section{References}

[1] Yuan Xiaoli, Animation role of design [J]. Film Review. 2006 (17).

[2] Mi Gaofeng. Liu ZiJian. Contemporary Context of the film and television animation audio-visual language [J]. Film Review. 2006 (18).

[3] Zhu Zhihong, Chen Jianqun, Yin Li. Teaching mode of theoretical and experimental practice combination in visual language course, Laboratory science. Vol. 17 No. 2014 
[4] Sha Qi. Discussion on the Teaching Practice of“Audio-visual Language” in New Media Age, Heilogjiang science, Vol . 2, No. 6, 2011. 